\title{
PENGARUH GOD CONSCIOUNESS DAN KARAKTER WIRAUSAHAWAN TERHADAP KEBERHASILAN USAHA DI LANGSA TOWN SQUARE
}

\author{
Safwan Kamal \\ Institut Agama Islam Negeri Langsa \\ safwankamal@iainlangsa.ac.id \\ Nurjannah \\ Institut Agama Islam Negeri Langsa \\ nurjannah@iainlangsa.ac.id \\ Rahmah Susanti \\ Institut Agama Islam Negeri Langsa \\ rahmahsusanti98@gmail.com
}

\begin{abstract}
This study aims to determine the effect of god consciousness and entrepreneur behavior on sales success in Langsa Town Square. The method used is a quantitative approach. Data was collected using a questionnaire with a sample of 64 respondents and the sampling technique used probability sampling. The data analysis method used is multiple linear regression analysis using SPSS software version 16.0. This study uses a Likert scale measurement. The results of this study are based on a partial test, the god consciousness variable has an effect on sales success with a significant value of 0.002 which is smaller than the value of 0.05 . The entrepreneur behavior variable has an effect on business success as indicated by a significant value of 0.000 which is smaller than 0.05 . simultaneously, these two variables have a significant effect on business success and the value of $\mathrm{R}$ square is 0.739 or $73.9 \%$.
\end{abstract}

Keywords: God Consciousness, entrepreneur behavior and business success.

\begin{abstract}
Abstrak
Penelitian ini bertujuan untuk mengetahui pengaruh god consciousness dan karakter wirausahawan terhadap keberhasilan usaha di langsa town square. Metode yang di gunakan yaitu pendekatan kuantitatif. Pengumpulan data dilakukan menggunakan kuesioner dengan sampel 64 responden dengan teknik pengambilan sampel menggunakan probability sampling. Metode analisis data yang digunakan adalah analisis regresi linier berganda menggunakan bantuan software SPSS versi 16.0. Penelitian ini menggunakan pengukuran skala likert. Hasil dari penelitian ini berdasarkan uji secara parsial,
\end{abstract}


variabel god consciousness berpengaruh terhadap keberhasilan usaha dengan nilai signifikan sebesar 0,002 lebih kecil dari nilai 0,05. Variabel karekter wirausahawan berpengaruh terhadap keberhasilan usaha yang ditunjukan dengan nilai signifikan sebesar 0,000 lebih kecil dari 0,05. Sedangkan secara simultan, kedua variabel tersebut memiliki pengaruh yang signifikan terhadap keberhasilan usaha dan nilai $\mathrm{R}$ square sebesar 0,739 atau 73,9\%.

Kata Kunci: God Consciouness, Karakter Wirausahawan dan Keberhasilan Usaha.

\section{Pendahuluan}

Saat ini keberadaan UMKM tidak dapat dihapuskan ataupun di hindarkan dari masyarakat bangsa. Karena dalam hal pendistribusian pendapatan masyarakat keberadaannya sangat bermanfaat. Selain itu juga mampu menciptakan kreatifitas yang sejalan dengan usaha untuk mempertahankan dan mengembangkan unsur-unsur tradisi dan kebudayaan masyarakat setempat. Di sisi lain, UMKM juga mampu menyerap tenaga kerja dalam skala yang besar mengingat jumlah penduduk Indonesia yang besar sehingga hal ini dapat mengurangi tingkat pengangguran. Dari sinilah dapat diketahui bahwa keberadaan UMKM yang bersifat padat karya, menggunakan teknologi yang sederhana dan mudah dipahami mampu menjadi sebuah wadah bagi masyarakat untuk bekerja (Anggraeni, Feni Dwi, n.d.).

Pertumbuhan perekonomian di Indonesia tidak lepas dari peran sektor Usaha Mikro, Kecil, dan Menengah (UMKM). UMKM memiliki peran penting dalam pembangunan ekonomi nasional serta pendistribusian beberapa hasil pembangunan (Huda et al., 2019). UMKM juga telah membuktikan dapat bertahan dalam kondisi krisis. Menurut Kementrian Perindustrian (2019), UMKM mampu memberikan kontribusinya terhadap Produk Domestik Bruto (PDB) sebesar 60.3\% dan kontribusi terhadap penyerapan tenaga kerja sebesar 97.2\%. Pada Tabel 1 terlihat perkembangan UMKM pada tahun 2016-2017 yang mengalami peningkatan yaitu sebesar 1271440 unit atau 2.06\%. Berdasarkan data tersebut, jumlah pelaku UMKM yang meningkat dari tahun 2016 sampai tahun 2017 menjadi potensi UMKM terhadap pertumbuhan perekonomian di Indonesia (Rahayu, Retno Jati, Sania Sara Monica, 2019).

Tabel 1.1 Perkembangan UMKM tahun 2016-2017

\begin{tabular}{|l|l|l|l|c|}
\hline \multirow{2}{*}{ Skala usaha } & \multicolumn{2}{|c|}{ Tahun (Unit) } & \multicolumn{2}{c|}{ Pertumbuhan } \\
\cline { 2 - 5 } & \multicolumn{1}{|c|}{2016} & \multicolumn{1}{|c|}{2017} & $\begin{array}{c}\text { Jumlah } \\
\text { (unit) }\end{array}$ & Pangsa (\%) \\
\hline Usaha Mikro & $\begin{array}{l}60.863 . \\
578\end{array}$ & 62.106 .900 & 1.243 .322 & 2.04 \\
\hline Usaha Kecil & 731.047 & 757.090 & 26.043 & 3.56 \\
\hline $\begin{array}{l}\text { Usaha } \\
\text { Menengah }\end{array}$ & 56.550 & 58.627 & 2.075 & 3.67 \\
\hline Total UMKM & 61.651 .176 & 62.922 .617 & 1.271 .440 & 2.06 \\
\hline
\end{tabular}


Program UMKM (pengembangan Usaha Mikro, Kecil, dan Menengah) sebagai salah satu instrument untuk menaikkan daya beli masyarakat, pada akhirnya akan menjadi katup pengaman dari situasi krisis moneter. Dalam menggerakkan perekonomian nasional pengembangan UMKM menjadi sangat strategis, mengingat kegiatan usahanya mencakup hampir semua lapangan usaha sehingga kontribusi UMKM menjadi sangat besar bagi peningkatan pendapatan bagi kelompok masyarakat berpendapatan rendah atau miskin (Anggraeni, Feni Dwi, n.d.).

Kemiskinan merupakan persoalan besar dalam masyarakat (Kamal, 2018). Untuk mengurangi kemiskinan dan pengangguran di Indonesia, pemerintah menumbuhkan sikap kewirausahaan pada masyarakat. Kewirausahaan menjadi perhatian penting dalam perekonomian suatu bangsa. Kemajuan atau kemunduran suatu bangsa ditentukan oleh adanya wirausahawan. Bangsa tidak akan ada kemajuan jika bangsa tersebut tidak memiliki sumber daya manusia dengan jiwa kewirausahaan. Maka dari itu, dapat dikatakan bahwa kemajuan suatu bangsa dapat dilihat melalui keberadaan dan peran wirausahawannya. Pada sejarah ekonomi negara-negara maju, keberadaan para wirausahawan sejalan dengan proses perubahan sosial atau menjadi revolusi tersembunyi pada bangsa tersebut. Keberadaan wirausaha terlihat nyata pada peningkatan pendapatan nasional, dinamika ekonomi, dan proses modernisasi ekonomi yang berkelanjutan. penjelasan tersebut membuktikan bahwa peran wirausahawan yang sangat penting dalam menentukan kemajuan bangsanya. Masih sedikit jumlah wirausahawan di Indonesia dan lebih rendah dibandingkan negara-negara tetangga seperti Thailand Malaysia dan Singapura yang telah mencapai lebih dari empat persen (Ariesa, 2013).

Wirausahawan menciptakan lapangan pekerjaan bagi masyarakat sehingga dapat mengurangi jumlah pengangguran dan meningkatkan pendapatan masyarakat. Berkurangnya jumlah pengangguran akan berimplikasi pada penurunan angka kemiskinan. Jumlah wirausahawan yang meningkat berimplikasi pada semakin banyak lapangan kerja yang diciptakan, sehingga dapat berperan dalam mendukung perekonomian negara (Ariesa, 2013).

Permasalahan yang sangat sering ditangani adalah masalah kemiskinan. Bagi setiap negara khususnya Indonesia kemiskinan merupakan persoalan yang memerlukan perhatian khusus dalam penyelesaiannya. Menurut BPS Kemiskinan dipandang sebagai ketidakmampuan dari sisi ekonomi untuk memenuhi kebutuhan dasar makanan dan bukan makanan yang diukur dari sisi pengeluaran. Jadi penduduk miskin adalah penduduk yang memiliki ratarata pengeluaran perkapita perbulan di bawah garis kemiskinan (Kamal, 2019).

Badan Pusat Statistik (BPS) pertama kali melakukan penghitungan jumlah dan persentase penduduk miskin pada tahun 1984. Pada saat itu penghitungan jumlah dan persentase penduduk miskin mencakup periode 1976-1981 dengan menggunakan data modul konsumsi Survei Sosial Ekonomi 
Nasional (Susenas). Sejak tahun 1984, setiap tiga tahun sekali BPS secara rutin mengeluarkan data jumlah dan persentase penduduk miskin (Hidayat, Fajar, 2018).

Pada bulan september 2017, jumlah penduduk miskin (penduduk dengan pengeluaran per kapita per bulan di bawah garis kemiskinan) di aceh mencapai 829 ribu orang (15,92 persen), berkurang sebanyak 42 ribu orang dibandingkan dengan penduduk miskin pada maret 2017 yang jumlahnya 872 ribu orang $(16,89$ persen), salah satunya penduduk miskin yang berada di Provinsi Aceh yaitu Kota Langsa. Jumlah dan Persentase Penduduk Miskin, P1, P2 dan Garis Kemiskinan Kota Langsa tahun 2017-2019.

\section{Gambar 1.1}

\begin{tabular}{|c|c|c|c|}
\hline \multirow{2}{*}{ Kategori Kemiskinan } & & & \multirow[b]{2}{*}{2019} \\
\hline & 2017 & 2018 & \\
\hline Jumlah Penduduk Miskin (000) & 19.20 & 18.73 & 18.62 \\
\hline Persentase Penduduk Miskin (P0) & 11.24 & 10.79 & 10.57 \\
\hline Indeks Kedalaman (P1) & 1.67 & 1.34 & 1.78 \\
\hline Indeks Keparahan (P2) & 0.41 & 0.28 & 0.44 \\
\hline Garis kemiskinan (Rp/Kapita/Bulan) & 347056 & 371267 & $\begin{array}{l}380906 \\
\text { uiturva1 }\end{array}$ \\
\hline
\end{tabular}

Kota Langsa menciptakan lapangan pekerjaan yaitu membuka usaha sendiri atau menjalankan bisnis. Khususnya di Langsa Town Square, terdapat wirausahaawan yang menjalankan usahanya masing-masing. Keberhasilan usaha seseorang tergantung pada banyak hal, seperti kejujuran dalam setiap perkataan dan perbuatan, kemauan bekerja keras agar mencapai tujuan, memiliki jiwa kepemimpinan, menepati janji, sabar dalam menghadapi hambatan dan tantangan, melakukan pencatatan dan pembukuan yang rapi dalam berbisnis, tidak mudah putus asa dan tidak lupa selalu berdo'a kepada Allah S.W.T. Hal itu semua telah diatur dalam Alqur'an dan hadits. Maka dari itupenerapan nilai-nilai kewirausahaan Islami yang telah diatur dalam Alqur'an dan Hadits sangat mempengaruhi keberhasilan seseorang dalam berbisnis (Rimiyati, 2016).

Unsur karakter dari wirausahawan merupakan aspek vital dalam perspektif Islam sendiri. Hal ini dikarenakan keberhasilan usaha dalam Islam tidak hanya berorientasikan pada hasil tetapi juga pada proses. Karena bisnis dalam Islam terintergrasi dengan ibadah, maka proses bisnis tidak boleh mengandung kegiatan yang menyimpang dari nilai Islam. Proses dalam bisnis ini sangat ditentukan oleh perilaku yang merupakan manifestasi dari karakter wirausahawan itu sendiri (Subagyo, 2014).

Maka dari itu di perlukan wirausahawan yang memiliki karakter sesuai dengan yang di teladani oleh Al-Quran dan Hadis, akan tetapi dapat ditemui wirausahawan tidak memiliki karakter yang baik dalam melayani konsumen, contohnya mengabaikan konsumen yang datang. Hal ini juga dibuktikan dengan adanya pendapat dari Muhammad Syakir Sula dan Hermawan Kartajaya, menurut mereka pemasaran Islam memiliki dua karakteristik. 
Pertama yaitu spiritualitas dimana setiap kegiatan pemasaran harus sesuai dengan ajaran Al-Qur'an dan Hadits. Seorang pemasar Islam harus meyakini bahwa hukum Islam adalah hukum terbaik yang harus dipakai dalam menjalankan aktifitas pemasaran. Karakteristik kedua yaitu etika, dimana etika Islam yang bersumber dari Al-Qur'an dan Hadits harus dijalankan oleh setiap pemasar Islam. Dengan selalu menjaga etika bisnis yang sesuai dengan ajaran Islam, maka akan terbangun budaya kerja Islami yang dapat menyeimbangkan kepentingan dunia dan akhirat (Fathoni, 2018).

Demi mendapatkan kepentingan di dunia dan di akhirat, wirausahawan seharusnya menerapkan nilai Islam dalam menjalankan bisnisnya, namun demikian di sisi lain terdapat wirausahawan yang tidak sesuai dengan nilainilai Islam, contohnya seperti mengambil keuntungan yang banyak demi mendapatkan keuntungan yang maksimal. Syaikh Abdul Aziz bin Abdillah bin Baz ketika di tanya mengenai standar keuntungan syar'i dalam berdagang, ia menjelaskan bahwa perlu diketahui tidak ada batasan keuntungan (menurut syari'at). Keuntungan bisa saja banyak, bisa pula sedikit. Kecuali jika sudah ada batasan harga di pasaran dengan harga tertentu, maka tidak boleh konsumen dikelabui saat itu. Bahkan sudah sepantasnya si pedagang memberitahukan pada pelanggannya bahwa barang ini ada dengan harga sekian dan sekian, namun harga yang ia patok adalah demikian, demi menjalankan bisnis dalam Islam (Nasution, 2013).

Berbisnis dalam Islam terintegrasi dengan ibadah dan tidak boleh mengandung kegiatan yang menyimpang dari nilai Islam, contohnya wirausahawan yang melangsungkan kegiatan bisnisnya dan tidak menutup toko ketika azan berkumandang. Di haramkan melakukan kesibukan yang menyebabkan seseorang meninggalkan kewajiban shalat. Keharaman ini tidak terkecuali pada shalat fardhu. Kewajiban tersebut tidak boleh digantikan dengan kesibukan melakukan jual beli atau kesibukan lainnya, ketika panggilan shalat sudah berkumandang mengajak manusia datang ke Masjid.

Berdasarkan masalah tersebut menjadi penting untuk melakukan penelitian mengenai "Pengaruh God Consciouness dan Karakter Wirausahawan Terhadap Keberhasilan Usaha Di Langsa Town Square".

\section{Metode Penelitian}

Pada penelitian ini mengunakan pendekatan kuantitatif, data yang digunkan dalam penelitian ini adalah data sekunder dan data primer. Dengan menekankan pada pengujian teori melalui pengukuran variabel penelitian dengan angka dan melakukan analisis data dengan prosedur statistik (SPSS). Dalam proses pengambilan data yang diginakan dalam penelitian ini ditentukan dengan menggunakan teknik probability sampling (Sugiyono, 2017). Pengukuran variabel god consciousness, karakter wirausahawan dan keberhasilan usaha menggunakan skala likert dengan tahapan-tahapan uji validitas, uji reliabilitas dan uji asumsi klasik sebelum menganalisis dengan regresi berganda. 


\section{Hasil dan Pembahasan}

Berdasarkan pengujian variabel dengan analisis regresi berganda, dengan melibatkan variabel yang di teliti yaitu god consciousness(X1), karakter wirausahawan (X2), dan keberhasilan usaha (Y). Maka hasilnya adalah:

Tabel 1

Uji Analisis Regresi Linier Berganda

Coefficientsa

\begin{tabular}{|c|c|c|c|c|c|c|}
\hline \multirow{2}{*}{\multicolumn{2}{|c|}{ Model }} & \multicolumn{2}{|c|}{$\begin{array}{l}\text { Unstandardized } \\
\text { Coefficients }\end{array}$} & \multirow{2}{*}{\begin{tabular}{|c}
$\begin{array}{c}\text { Standardiz } \\
\text { ed } \\
\text { Coefficient } \\
\text { s }\end{array}$ \\
Beta
\end{tabular}} & \multirow[b]{2}{*}{$\mathrm{T}$} & \multirow[b]{2}{*}{ Sig. } \\
\hline & & B & Std. Error & & & \\
\hline 1 & (Constant) & .476 & 1.682 & & .283 & .778 \\
\hline & $\begin{array}{l}\text { God Consciouness } \\
\text { (X1) }\end{array}$ & .280 & .086 & .257 & 3.258 & .002 \\
\hline & $\begin{array}{l}\text { Karakter } \\
\text { wirausahawan (X2) }\end{array}$ & .691 & .079 & .690 & 8.748 & .000 \\
\hline
\end{tabular}

a. Dependent Variable: Keberhasilan Usaha(Y)

Berdasarkan tabel di atas persamaan regresi linierBerganda pada penelitian ini yaitu:

$\mathrm{Y}=0,476+0,280(\mathrm{x} 1)+0,691(\mathrm{x} 2)$

Dari persamaan analisis regresi regresi berganda di atas maka di jelaskan sebagai berikut:

a. Nilai konstanta persamaan di atas adalah sebesar 0,476. Angka tersebut menunjukan bahwa jika tidak terjadi perubahan variabel god consciousness dan karakter wirausahawan (nilai X1 dan X2 adalah 0) maka keberhasilan usaha sebesar 0,476 satuan.

b. Nilai koefisien variabel god consciousness(X1) yaitu sebesar 0,280. Artinya jika variabel X1 mengalami kenaikan sebesar 1 satuan persen maka nilai variabel akan naik sebesar 0,280 \%.

c. Nilai koefisien variabel karakter wirausahawan (X2) yaitu sebesar 0,691. Artinya jika variabel X2 menagalami kenaikan sebesar1 satuan persen maka nilai variabel naik sebesar 0,691\%. 
Tabel 2

Hasil Uji T

Coefficients ${ }^{\mathrm{a}}$

\begin{tabular}{|c|c|c|c|c|c|c|c|c|}
\hline \multirow{2}{*}{\multicolumn{2}{|c|}{ Model }} & \multicolumn{2}{|c|}{$\begin{array}{l}\text { Unstandardized } \\
\text { Coefficients }\end{array}$} & \multirow{2}{*}{$\begin{array}{c}\text { Standard } \\
\text { ized } \\
\text { Coefficie } \\
\text { nts }\end{array}$} & \multirow[b]{2}{*}{$\mathrm{T}$} & \multirow[b]{2}{*}{ Sig. } & \multicolumn{2}{|c|}{$\begin{array}{l}\text { Collinearity } \\
\text { Statistics }\end{array}$} \\
\hline & & B & $\begin{array}{l}\text { Std. } \\
\text { Error }\end{array}$ & & & & $\begin{array}{c}\text { Tolera } \\
\text { nce }\end{array}$ & VIF \\
\hline & (Constant) & .476 & 1.682 & & .283 & .778 & & \\
\hline & God & & & & & & & \\
\hline & $\begin{array}{l}\text { Consciousness } \\
\text { (XI) }\end{array}$ & .280 & .086 & .257 & 3.258 & .002 & .666 & 1.502 \\
\hline & Karakter & & & & & & & \\
\hline & $\begin{array}{l}\text { Wirausahawan } \\
\text { (X2) }\end{array}$ & .691 & .079 & .690 & 8.748 & .000 & .666 & 1.502 \\
\hline
\end{tabular}

a. Dependent Variable: Keberhasilan

Usaha (Y)

Jika nilai Sig. < 0,05 maka artinya variabel independen (X) secara parsial berpengaruh terhadap variabel $(\mathrm{Y})$. Dari hasil pengujian diatas dapat di simpulkan:

\section{God consciousness berpengaruh terhadap keberhasilan usaha di Langsa Town Square}

God consciousness (kesadaran akan tuhan), Arti sadar dalam kamus ilmiah adalah ingat akan dirinya; siuman; merasa dan insyaf akan dirinya; permulaan; depan. Dengan adanya kesadaran agama dalam diri seseorang yang akan ditunjukan melalui aktivitas keagamaan, maka munculah pengalaman beragama.

God consciousness (X1) berpengaruh terhadap keberhasilan usaha. Hal ini di buktikan dari nilai signifikan variabel god consciousness yakni 0,002 < 0,05, yang artinya bahwa pengaruh yang terjadi antara variabel god consciousness dengan keberhasilan usaha adalah signifikan secara statistik. hasil penelitian menunjukan $\mathrm{Ha}_{1}$ diterima. Dengan demikian god consciouness berbanding lurus dengan keberhasilan usaha.

Hasil dari penelitian ini di dukung dari penelitian Putri Eka Ayuni Subagyo yang berjudul Keterkaitan Antara Karakter Ideal Wirausahawan Dalam Perspektif Islam Dengan Keberhasilan Usaha: Survei Persepsi Wirausahawan UMKM Di Bogor, mengatakan bahwa god consciouness berpengaruh positif terhadap keberhasilan usaha. 


\section{Karakter wirausahawan berpengaruh terhadap keberhasilan usaha di Langsa Town Square}

Karakter merupakan reputasi seseorang, suatu kualitas positif yang dimiliki seseorang, sehingga membuatnya menarik dan atraktif; dan seseorang yang memiliki kepribadian yang eksentrik. Karakter wirausahawan (X) berpengaruh terhadap keberhasilan usaha. Hal ini di buktikan dari nilai signifikan variabel karakter wirausahawan yakni $0,000<0,05$, yang artinya bahwa pengaruh yang terjadi antara variabel karakter wirausahawan dengan keberhasilan usaha adalah signifikan secara statistik. hasil penelitian ini menunjukan $\mathrm{Ha}_{2}$ diterima.

penelitian ini sependapat dengan penelitian yang dilakukan oleh Taufik Hidayat yang berjudul Karakteristik Wirausaha Dan Praktek Manajemen Berperspektif Islam Serta Hubungannya Terhadap Kesuksesan Agribisnis (Kasus Tiga Wirausaha Di Kabupaten Bogor Dan Sukabumi), mempunyai salah satu variabel karakter wirausahawan yang berpengaruh terhadap kesuksesan terhadap Agribisnis.

Tabel 3

Hasil Uji Simultan (Uji F)

ANOVA ${ }^{b}$

\begin{tabular}{|c|c|c|c|c|c|c|}
\hline \multicolumn{2}{|c|}{ Model } & $\begin{array}{l}\text { Sum of } \\
\text { Squares }\end{array}$ & Df & $\begin{array}{c}\text { Mean } \\
\text { Square }\end{array}$ & $\mathrm{F}$ & Sig. \\
\hline \multirow[t]{3}{*}{1} & Regression & 124.054 & 2 & 62.027 & 90.202 & $.000^{a}$ \\
\hline & Residual & 41.946 & 61 & .688 & & \\
\hline & Total & 166.000 & 63 & & & \\
\hline
\end{tabular}

a. Predictors: (Constant), Karakter Wirausahawan (X2), God Consciousness (XI)

b. Dependent Variable: Keberhasilan Usaha (Y)

Apabila nilai Sig. < 0,05 maka artinya variabel independen (X) secara simultan berpengaruh terhadap variabel dependen $(\mathrm{Y})$. jadi dari hasil pengujian diatas dapat disimpulkan bahwa god consciousnes (X1) dan karakter wirausahawan (X2) secara simultan berpengaruh terhadap keberhasilan usaha (Y). 


\section{Tabel 4}

Hasil Uji Koefisien Determinan $\left(R^{2}\right)$

Model Summaryb

\begin{tabular}{|l|r|r|r|r|r|}
\hline Model & $\mathrm{R}$ & R Square & $\begin{array}{c}\text { Adjusted R } \\
\text { Square }\end{array}$ & $\begin{array}{c}\text { Std. Error of } \\
\text { the Estimate }\end{array}$ & $\begin{array}{c}\text { Durbin- } \\
\text { Watson }\end{array}$ \\
\hline 1 & $.864 \mathrm{a}$ & .747 & .739 & .82924 & 2.061 \\
\hline
\end{tabular}

a. Predictors: (Constant), Karakter Wirausahawan (X2), God Consciousness (XI)

b. Dependent Variable: Keberhasilan Usaha (Y)

Table di atas adalah table yang menunjukkan besar pengaruh kedua variable terhadap Y, dari data di atas nilai Adjusted $R$ Square $=0,739 \times 100=$ $73,9 \%$ yang menunjukkan bahwa kontribusi X1 dan X2 terhadap keberhasilan usaha secara simultan adalah $73,9 \%$ dan selebihnya dipengaruhi oleh faktor lain.

\section{Penutup}

Berdasarkan hasil dari penelitian ini, dapat di simpulkan bahwa secara parsial god consciousness, dan karakter wirausahawan berpengaruh positif terhadap keberhasilan usaha di Langsa Town Square. Sedangkan secara simultan god consciousness, dan karakter wirausahawan berpengaruh secara simultan terhadap keberhasilan usaha di Langsa Town Square, hasil penelitian menunjukan bahwa nilai sig sebesar 0,000 < 0,05. Jadi dapat disimpulkan besarnya kontribusi X1 dan X2 terhadap Y secara simultan adalah 73,9\% dan selebihnya dipengaruhi oleh faktor diluar dari penelitian ini.

Adapun saran-saran dari penelitian ini adalah:

a. Bagi peneliti selanjutnya disarankan agar dapat menambah variabel independen untuk lebih mendalami tentang pemasaran, agar hasil yang didapat akan memperkuat penelitian yang ada.

b. Bagi wirausahawan di Langsa Town Square untuk dapat meningkatkan bersikap ramah, peduli, kecepatan, ketanggapan, kenyamanan (kebersihan dan keamanan) bagi konsumen. 


\section{Daftar Pustaka}

Anggraeni, Feni Dwi, D. (n.d.). Pengembangan Usaha Mikro, Kecil, Dan Menengah (Umkm) Melalui Fasilitasi Pihak Eksternal Dan Potensi Internal (Studi Kasus Pada Kelompok Usaha Emping Jagung Di Kelurahan Pandawangi Kecamatan Blimbing, Kota Malang). Jurnal Administrasi Publik, 1(6).

Ariesa, F. N. (2013). Pengaruh Perilaku Kewirausahaan terhadap Kinerja Usaha Tani Tembakau Virginia di Jawa Timur. Bogor: IPB.

Fathoni, M. A. (2018). Konsep Pemasaran Dalam Perspektif Hukum Islam. Jurnal Hukum Dan Syariah, 9(1).

Hidayat, Fajar, dkk. (2018). Data Dan Informasi Kemiskinan Kabupaten/Kota Tahun 2018.

Huda, M., Sudrajat, A., Muhamat, R., Mat Teh, K. S., \& Jalal, B. (2019). Strengthening divine values for self-regulation in religiosity: insights from Tawakkul (trust in God). International Journal of Ethics and Systems, IJOES-02-2018-0025. https://doi.org/10.1108/IJOES-02-2018-0025

Kamal, S. (2018). ZAKAT DAN INFAQ DALAM MENGURANGI PATOLOGI KEMISKINAN (STUDI PADA BAITUL MAL KOTA LANGSA). Ihtiyath: Jurnal Manajemen Keuangan Syariah.

Kamal, S. (2019). Fiqih Zakat Dan Teori Kemiskinan. Medan: Perdana Publishing.

Nasution, A. (2013). Peranan Kredit Usaha Rakyat (KUR) bagi Pengembangan UMKM di Kota Medan (Studi Kasus Bank BRI). Jurnal Ekonomi dan Keuangan, 1(3), 12.

Rahayu, Retno Jati, Sania Sara Monica, dkk. (2019). Analisis Perbandingan Metode Full Costing dann Variabel Costing untuk Menghitung Harga Pokok Produksi (Studi Kasus: CJH Catering Purwakarta). Jurnal Sakinah, 1(2), 25.

Rimiyati, H. \& M. M. (2016). Pengaruh Penerapan Nilai-Nilai Kewirausahaan Islami Terhadap Keberhasilan Usaha (Studi Pada Pengusaha UMKM Muslim Di Kota Yogyakarta). Yogyakarta: Universitas Muhammadiyah Yogyakarta.

Subagyo, P. E. A. (2014). Keterkaitan Antara Karakter Ideal Wirausahawan Dalam Perspektif Islam Dengan Keberhasilan Usaha: Survei Persepsi Wirausahawan UKM Di Bogor. Bogor: IPB.

Sugiyono, D. (2017). Metode Penelitian Kuatintatif, Kualitatif Dan R \& D. 